\title{
A INFLUÊNCIA DOS ELEMENTOS GRÁFICOS NOS LIVROS PARA CRIANÇAS NA CONTEMPORANEIDADE: ANÁLISE DE DUAS OBRAS DA COLEÇÃO UNIVERSIDADE DAS CRIANÇAS
}

\section{GRAPHIC ELEMENTS INFLUENCE IN BOOKS FOR CHILDREN IN THE CONTEMPORANEITY: ANALYSIS OF TWO WORKS FROM THE CHILDREN'S UNIVERSITY COLLECTION}

\author{
Hércules Tolêdo CORREA ${ }^{1}$ \\ Cleide de Araújo CAMPOS ${ }^{2}$
}

\begin{abstract}
Resumo: Pode-se dizer que o livro para crianças é um objeto artístico-cultural constituído por vários modos de linguagens. Dessa forma, partimos dos pressupostos da semiótica cultural, mais especificamente das teorizações sobre a multimodalidade, e procuramos identificar os aspectos tanto discursivos quanto educacionais de obras destinadas ao público infantil publicadas na contemporaneidade. Valemo-nos também de estudos sobre ilustração e projeto gráfico de livros infantis, tais como van der Linden (2011), Ramos (2013) e Paiva (2018). Este artigo, especificamente, centra-se na análise de dois livros da coleção Universidade das Crianças, publicada pelo selo Estraladabão, da Editora UFMG, em 2018: O que existe? O que não existe? e $O$ que é um livro? Os nomes dos profissionais envolvidos na produção das obras estão identificados ao longo deste artigo. Hoje em dia, podemos considerar o livro para crianças como um objeto com múltipla autoria (multi ou poliautoria): além do escritor e do ilustrador, os autores principais ou protagonistas, como denominamos neste texto, também estão envolvidos na produção da obra designers gráficos, editores e coordenadores editoriais especializados, leitores críticos, revisores de conteúdo e de linguagem, e muitas vezes também outros especialistas da área editorial e educacional, como publicitários, engenheiros do papel, tradutores, adaptadores, psicólogos, pedagogos e psicopedagogos, aos quais chamamos neste artigo de autoria secundária ou coadjuvante. Analisamos alguns elementos do projeto gráfico das obras selecionadas e da relação entre texto escrito, ilustração e design, seguindo a ordem: 1- Capa e quarta capa; 2- Formato do livro e outros elementos da materialidade; 3- Layout: forma como o texto escrito e o visual são apresentados na página, o que inclui uma série de elementos e de relações entre eles, como: tipo e tamanho de letra, espaço entre linhas e mancha gráfica (a área do impresso: texto escrito e ilustração). Destaca-se que a definição deste último elemento envolve a relação entre texto escrito e texto visual. Por fim, é importante dizer que este artigo faz parte de uma pesquisa coletiva desenvolvida no âmbito do Grupo MULTDIC - Multiletramentos e usos das tecnologias da informação e comunicação na Educação -, intitulada Literatura e visualidade: a importância do projeto gráfico em livros para crianças na contemporaneidade.
\end{abstract}

Palavras-chave: Livros para crianças. Multimodalidade. Projeto gráfico.

Abstract: Books for children are said to be an artistic-cultural object made up of several modes of languages. Thus, this paper departs from the assumptions of cultural semiotics, more specifically the theories about multimodality, and tries to identify both the discursive and educational aspects of works aimed at children published in contemporary times. Studies on illustration and graphic design of books for children, such as Nikolajeva and Scott (2011), van der Linden (2011), Ramos (2013) and Paiva (2018) are also used. This paper focuses specifically on the analysis of two books from Universidade da Criança [Children's University] collection, published by the label Estraladabão, by Federal University of Minas Gerais Press, in 2018: O que existe? O que não existe? (COSCARELLI, 2018) and O que é

\footnotetext{
${ }^{1}$ Doutor em Educação pela Universidade Federal de Minas Gerais. Professor da Universidade Federal de Ouro Preto. E-mail: herculest@uol.com.br

${ }^{2}$ Mestra em Educação pela Universidade Federal de Ouro Preto. Doutoranda em Educação pela UNESP-

Presidente Prudente. E-mail: emaildacleide6@gmail.com
} 
um livro? (RIBEIRO, 2018). Other professionals involved in the creation of the books are identified along this paper. Nowadays, books for children can be considered as an object of multiple authorship: besides the writer and the illustrator, the main authors or protagonists, as called in this paper, there are also other professionals, who were called secondary or coadjuvants authors, such as graphic designers, editors and specialized editorial coordinators, critical readers, content and language reviewers, and often also other editorial and educational specialists, such as advertisers, paper engineers, translators, adapters, psychologists, pedagogists and psychopedagogists. Some elements of the graphic design of the selected works and the relation between written text, illustration and design were analyzed in the following order: 1- Cover and fourth cover; 2- Format of the book and other elements of materiality; 3- Layout: how the written text and the visual are presented on the page, which includes a series of elements and relationships between them, such as: type and size of letter, space between lines and graphic spot (the area of the print: written text and illustration). It should be noted that the definition of this last element involves the relationship between written text and visual text. Finally, it is important to say that this paper is part of a collective research developed within the framework of the Group MULTDIC Multiliteracies and digital information and communication technologies, entitled Literatura e visualidade: a importância do projeto gráfico em livros para crianças na contemporaneidade [Literature and visuality: the importance of the graphic design in books for children in contemporaneity].

Keywords: Books for children. Multimodality. Graphic project.

\section{Introdução}

A leitura de uma obra para crianças, contemporaneamente, exige do leitor investimento cognitivo tanto na interpretação do texto verbal como das imagens e de vários outros elementos dos múltiplos modos que constituem o objeto livro em sua totalidade, dado o seu caráter cada vez mais multimodal. Tanto são múltiplas as linguagens das obras impressas destinadas às crianças (e muitas vezes também aos adultos) quanto o são os atores envolvidos na sua produção. Portanto, hoje em dia podemos dizer que as obras infantis são produzidas em múltipla autoria: além do escritor e do ilustrador, que podemos chamar de autores protagonistas, também estão envolvidos na sua produção designers gráficos, editores especializados, e muitas vezes também outros especialistas da área editorial e educacional, como publicitários, tradutores, adaptadores, revisores e pedagogos, que podemos chamar de autores coadjuvantes, ou secundários. Algumas vezes, ilustradores são também os responsáveis pelos projetos gráficos das obras. Também pode ocorrer que autores coadjuvantes possam alçar posições mais reservadas aos protagonistas, tendo em vista a importância do projeto gráfico, do design do livro.

Qual a importância, portanto, das relações entre palavras e imagens na leitura de uma obra infantil? Qual o papel desses elementos gráficos e dessa múltipla autoria para a produção de sentidos nas obras contemporâneas destinadas às crianças? Acreditamos que a 
multimodalidade das obras destinadas às crianças possibilita aos leitores uma experiência estética mais rica e, por vezes, amplia as possibilidades de sentido. Acreditamos, também, que o trabalho integrado da multiautoria colabore para a produção de uma obra mais sofisticada e, por que não dizer, mais complexa. Neste artigo, descrevemos e analisamos dois livros para crianças, para demonstrar tais pressuposições e com a intenção de fornecer aos nossos leitores (geralmente professores em formação ou em serviço) subsídios para o ensino. Num futuro próximo, esta pesquisa de natureza descritiva e analítica deverá ter uma segunda etapa, pelo viés da recepção infantil, momento em que daremos voz às crianças, para que nos apresentem suas interpretações. Para tanto, planejamos criar círculos de leitura e rodas de conversas sobre essas obras, coletando os comentários feitos por esses leitores, o público-alvo dos livros, em escolas da chamada Região dos Inconfidentes, área de atuação principal do grupo de pesquisa MULTDIC - Multiletramentos e usos das tecnologias digitais da informação e comunicação na Educação.

\section{Multimodalidade, texto multissemiótico, multiletramentos: pinceladas teóricas}

Na perspectiva de Cope e Kalantzis (2000), referendados por Lemke (2010), todo texto é multimodal (multissemiótico), requerendo, portanto, por parte de quem os produz e lê, letramentos múltiplos ou multiletramentos. Todo texto é constituído por muitas modalidades linguísticas, mas, muitas vezes, há uma modalidade predominante, como é o caso da literatura impressa para adultos. No caso dos livros destinados às crianças, os chamados livros-ilustrados (HUNT, 2010, p. 233) ${ }^{3}$, não podemos colocar a predominância do verbal sobre o não verbal e vice-versa. Embora o texto escrito possa ter sido gerado antes das imagens, no processo de produção do livro, no momento de sua leitura, ambos são processados conjuntamente pelo leitor e não há como atribuir predominância de um sobre o outro, se se propõe uma leitura e /ou uma mediação da leitura que procure $(\mathrm{m})$ dar conta do todo. O sujeito alfabetizado e letrado não lê e aprecia apenas um dos modos de linguagem de uma obra, mas todos os modos, de maneira holística. Noutras palavras, a experiência estética é de uma leitura global, que capta os diferentes modos, não atribuindo a um ou outro uma importância maior. Vale ressaltar, inclusive, que nessa perspectiva holística o todo é maior do que a soma das partes, ou seja, a

\footnotetext{
${ }^{3}$ Hunt (2010, p. 233) distingue livros-ilustrados de livros com ilustração. Os primeiros são obras que apenas existem a partir das versões ilustradas, enquanto os últimos apresentam versões ilustradas ou sem ilustrações ou, ainda, com ilustrações distintas, dependendo da edição.
} 
leitura é o resultado do processamento global da obra e não da soma do processamento de cada um dos modos de linguagem separadamente.

De acordo com Paiva (2018), o livro é um objeto múltiplo, constituído de muitas camadas de linguagens, muitas camadas de signos. O exercício do olhar na leitura de determinados livros - imagens que se transformam dependendo do ponto de vista - como o livro Pato! Coelho! (ROSENTHAL; LICHTENHELD, 2010) ou mesmo a clássica ilustração de O pequeno Príncipe (SAINT-EXUPÉRY, 2009), em que se pode visualizar uma imagem como um chapéu ou como uma serpente que engoliu um elefante, nos mostram como são múltiplas as interpretações. Em virtude do acesso às tecnologias digitais de informação e comunicação, cada vez os textos que circulam na sociedade são mais multimodais, das nossas mensagens via aplicativos de smartphones à mais refinada produção impressa para crianças e jovens.

Figura 1 - Reproduções de ilustração do livro O pequeno príncipe

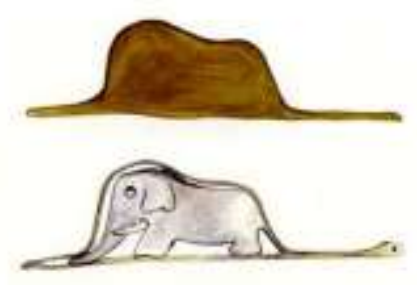

Fonte: http://bahiavitrine.blogspot.com/2010/10/isso-nao-e-um-chapeu.html

Uma das camadas de linguagem do livro é o design gráfico: a sua aparência e o seu layout, enfim, o que poderíamos chamar de "arquitetura do livro". Em obra pioneira sobre ilustração do livro para crianças, Camargo apresenta a seguinte definição:

Projeto gráfico é o planejamento de qualquer impresso: cartaz, embalagem, folheto,
jornal, revista etc. No caso do livro, o projeto gráfico abrange: formato, número de
páginas, tipo de papel, tipo e tamanho das letras, mancha (a parte impressa da página,
por oposição às margens), diagramação (distribuição de texto e ilustrações),
encadernação (capa dura, brochura etc.), o tipo de impressão (tipografia, offset etc),
número de cores de impressão etc. (CAMARGO, 1995, p. 16)

Já para as pesquisadoras Santos e Pimenta (2014), a partir de teóricos como Kress e van Leewen (2001), o design constitui o:

uso do recurso semiótico em todos os modos semióticos e combinações de modos semióticos, formas de expressão dos discursos no contexto de uma dada comunicação. [...] os discursos tomam forma a partir dos modos semióticos expressos (design) e que 
têm o potencial de significação destes (dos discursos).” (SANTOS; PIMENTA, 2014, p. 303)

Santos e Pimenta afirmam também, numa referência à Linguística SistêmicoFuncional $^{4}$, que o significado é organizado em três domínios: o design, a produção e a distribuição. A produção constitui o trabalho físico de articular o texto, a sua organização. Portanto, o designer gráfico organiza texto escrito e visual na página de um livro. Em relação ao estrato da distribuição, Kress e van Leeuwen (2001) afirmam que ele tende a ser considerado como não semiótico, pois ele se refere, em um primeiro nível, às tecnologias que podem ser usadas na preservação e transmissão da comunicação. Em um segundo nível, a distribuição tem o objetivo de transformar a comunicação, pois pode criar novas representações e interações, estendendo o significado semiótico e, consequentemente, mudando-o. Nessa perspectiva, para Kress (2010), vários Modos Semióticos (linguagem verbal, imagem, música, gestos, arquitetura, dentre outros) que são realizados a partir de várias modalidades sensoriais (visual, auditiva, tátil, olfativa, gustativa e cinética) passam a ser considerados como participantes do denominado fenômeno multimodal. Modos são recursos semióticos socialmente enquadrados e culturalmente dados para produzir significado. Imagem, escrita, layout, música, gestos, fala, imagem em movimento, trilha sonora e objetos em 3D são exemplos de modos usados na representação e na comunicação (KRESS, 2010, p. 79, tradução nossa).

Ao analisarem ilustrações de livros para crianças, Camargo (1995) e Mendes (2007) estabelecem algumas classificações. Camargo (1995) categoriza as ilustrações conforme suas funções em: 1) pontuação; 2) função descritiva; 3) função narrativa; 4) função simbólica; 5) função expressiva/ética; 6) função estética; 7) função lúdica; 9) função metalinguística. André Mendes (2007), conforme Paiva (2018), menciona três formas de relações entre textos escritos e imagens: 1) equivalência ou ratificação; 2) similitude conjugada a novas ideias; 3) estranhamento. Mendes (2007, p. 98) cita o caso de ilustrações de Angela Lago, que causam "estranhamento" aos leitores tendo em vista os seus desenhos estilizados, que apenas sugerem algo ao leitor, distanciando-se de imagens mais realistas. Neste artigo, fundamentamo-nos nas classificações apontadas por ambos os pesquisadores, mas sem necessariamente categorizar as obras e suas respectivas páginas. As classificações nos servem como ponto de partida para as descrições analíticas que fazemos.

Outra ideia na qual nos apoiamos na escrita deste artigo é a do livro como metáfora de uma orquestra - músicos e ouvintes, múltiplos autores e múltiplos leitores - estabelecem

\footnotetext{
${ }^{4}$ Teoria segundo a qual a linguagem é vista como uma atividade social.
} 
relações parecidas durante suas experiências estéticas (SMITH, B. A.; TAN, S.; PODLASOV, A.; O’HALLORAN, K. L., 2009). A produção de um livro constitui um "arranjo de significados", uma "orquestração de sentidos" e a leitura também pode e deve se constituir em múltiplas interpretações desses arranjos. Cabe ao leitor fruir esteticamente a obra como um todo, identificando e contemplando cada um dos vários elementos que a constituem. Quando ouvimos uma orquestra, ouvimos simultânea ou sucessivamente (harmonia e melodia) um conjunto de instrumentos, mas podemos procurar ouvir melhor um deles, em específico, num ou noutro momento. Pensamos que a leitura de um livro-ilustrado ocorre da mesma maneira. Smith et al. (2009) propõem nomear tal modelo como a investigação da orquestração de significados, o que supõe, portanto, a abertura do campo analítico da multimodalidade.

Resumidamente, então, podemos dizer que diferentes modalidades sensoriais (visual, auditiva, tátil, olfativa, gustativa e cinética) estão envolvidas na leitura de um livro e que também ocorre uma conjunção de sentidos durante a leitura. Temos exemplos, no mercado infantil, de livros "sonoros", como Vrum Clap Clap (YOYO BOOKS, 2016), o livro-matraca. Há livros cinéticos, como Formas (GEORGE, 2016), com a presença de folhas transparentes que fazem com que determinadas imagens se movimentem e se transformem. Muitos livros brinquedos, como os livros pop-up, também têm forte apelo cinético (PAIVA, 2018).

A seguir, tratamos da configuração geral dos livros da coleção Universidade das Crianças e passamos à descrição e análise de duas obras. Avaliamos alguns elementos do projeto gráfico das obras selecionadas e da relação entre texto escrito, ilustração e design, seguindo a ordem: 1- Capa e quarta capa; 2- Formato do livro e outros elementos da materialidade; 3- Layout: forma como o texto escrito e o visual são apresentados na página, o que inclui uma série de elementos e de relações entre eles, como: tipo e tamanho de letra, espaço entre linhas e mancha gráfica (a área do impresso: texto escrito e ilustração).

\section{Configuração geral dos livros da coleção Universidade das Crianças}

Os livros da coleção Universidade das Crianças têm um formato retangular vertical e um tamanho $(21 \mathrm{~cm} \times 16 \mathrm{~cm})$ padronizados. Suas capas são feitas de papel cartonado, com gramatura superior à das páginas, que foram impressas em papel couché brilhante. Possuem entre 24 e 28 páginas com dois grampos. O texto escrito sobrepõe-se às imagens na mancha gráfica. As páginas não apresentam margens e muitas imagens são sangradas, ou seja, continuam (no imaginário do leitor) após acabar as páginas. O texto escrito geralmente ocupa no máximo 30\% das páginas, com algumas palavras com uso do bold (negrito). 


\section{Descrição analítica do livro $O$ que existe? $O$ que não existe?}

A intenção das seções três e quatro é apresentar ao leitor os livros da coleção, por meio de uma descrição que adjetivamos como analítica, uma vez que procuramos, ao descrever a obra, também analisar os possíveis efeitos de sentido proporcionados pelas suas diferentes modalidades de linguagem.

A capa do livro O que existe? O que não existe? (COSCARELLI, 2018) traz o título da obra acompanhado da autoria do texto e da ilustração, respectivamente os nomes de Carla Coscarelli e Cláudia Jussan, as quais chamamos aqui de autoras protagonistas. O canto superior esquerdo traz também a série (Ficção) e o canto inferior direito traz o nome do selo (Estraladabão), ambas as informações aparecem como logomarcas que se repetem nos demais livros da coleção. A imagem da capa mostra uma sereia loira tecendo tranquilamente, em uma confortável poltrona, acompanhada de um gato adormecido e de um solitário peixe em um aquário. Percebem-se ainda quadros na parede do ambiente, um smarphone ou tablet apoiado no braço da poltrona e peixes que nadam tranquilamente na parte inferior, sugerindo tratar-se do fundo do mar. Percebe-se já pela capa o jogo entre o real e o ficcional, com elementos tanto de um mundo quanto do outro. Instaura-se, desta maneira, o pacto de leitura proposto pela obra, o ficcional.

Figura 2 - Capa do livro O que existe? O que não existe?

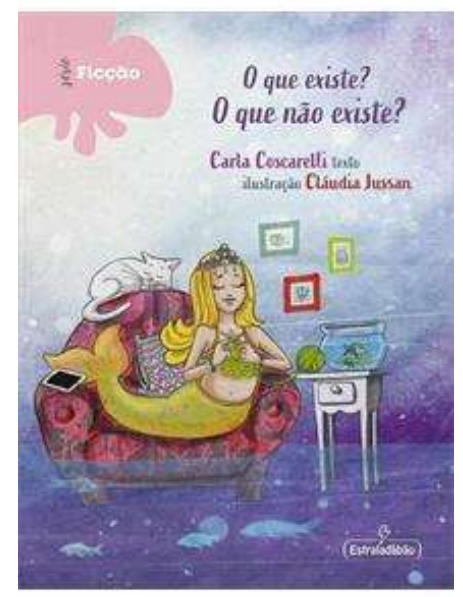

Fonte: https://www.travessa.com.br/o-que-existe-o-que-nao-existe/artigo/0c5b3d99-cc75-4a75-a552$4 \mathrm{bb} 139 \mathrm{fa} 74 \mathrm{eb}$

A quarta capa traz os nomes de algumas das séries da coleção na parte superior, como se fosse um fichário, o restante da ilustração sangrada da capa, e um pequeno texto que incentiva e convida a leitura, juntamente com o título da obra. Aparecem ainda as logomarcas da coleção 
Universidade das Crianças e do apoio do CNPq, além do registro do ISBN no canto inferior esquerdo. A segunda e terceira capas trazem imagens que se repetem no miolo do livro, como bolhas de ar na água, folhas, fantasminhas, sacis e barquinhos de papel. Esses elementos paratextuais contribuem para a continuidade do pacto de leitura proposto pela obra como um todo.

O verso da folha de rosto traz informações tais como a ficha catalográfica, autoridades da UFMG e da sua editora e informações sobre a aqui chamada autoria coadjuvante da obra. Há também um pequeno texto dirigido ao leitor, apresentando o selo e o projeto Universidade das Crianças. Esses componentes têm cunho informativo e, ao mesmo tempo, constituem também um convite à leitura, explicitando-se para o leitor alguns elementos que normalmente são muito mais úteis a possíveis mediadores de leitura adultos do que para as crianças, públicoalvo das obras.

A coleção possui várias séries, como Ficção e Papel, como as duas representadas neste artigo. Os livros são publicados pelo selo Estraladabão, criado exclusivamente para ela. O nome da coleção é inspirado no neologismo que dá título ao livro infantil Estraladabão-tão-tão, o trovão, de Angelo Machado, profissional da área biológica e escritor de livros para crianças, professor do mesmo instituto da idealizadora do projeto Universidade das Crianças, Débora Reis, na UFMG.

A obra $O$ que existe? O que não existe? tem como autora do texto Carla Coscarelli e foi ilustrado por Cláudia Jussan, conforme explicitado na capa. Essas são, portanto, as autoras principais do livro, porque dessas duas figuras nasce a ideia original da obra. Normalmente, o ilustrador faz o trabalho a partir do texto escrito. Esta é a forma mais comum dos produtos que temos no mercado, mas outras formas de produção também podem acontecer, como uma produção conjunta, as intervenções do ilustrador que podem ser aceitas ou não pela autoria do texto, e outras formas de trocas possíveis entre os profissionais. Se observamos a página da ficha catalográfica, encontramos outros nomes e funções que constituem o que chamamos aqui de autoria secundária ou coadjuvante: projetistas gráficos, diagramadores, revisores, coordenadores de textos e leitores críticos, que são os profissionais e empresas citados no caso deste livro. Assim, identificamos na obra em questão, um produto construído a muitas mãos, alguns com maior ou menor participação, o que nos leva à consideração dessa autoria múltipla, fundamental para a construção de um objeto multidimensional em termos de linguagem (a verbal, a visual, a verbo-visual) e também em termos de suas funções: objeto artístico, educacional, informativo, de entretenimento, dentre outras. 
As diferentes experiências estéticas (como a audição de uma música, a audiência a um filme ou a contemplação de um quadro) e a leitura de textos diversos (literários, principalmente, mas também os informativos e até as listas, por exemplo) também ensejam a participação do fruidor como um coautor do texto. Essa participação, na presente obra, não acontece apenas no plano das ideias, da imaginação, mas também no plano concreto, haja vista o convite e o próprio projeto gráfico do livro, que traz, nas suas páginas 12 e 13, texto escrito e espaço para que o leitor "imagine" e "desenhe" no próprio livro:

Quando lemos um livro, imaginamos os personagens, os lugares, os acontecimentos. Ficamos amigos das personagens ou ficamos com muita raiva delas. Sentimos tristeza e dó delas em alguns momentos. Em outros, sentimos alegria, vibramos com elas.

O fragmento anterior nos mostra algumas sensações que podem nos ocorrer durante a chamada experiência estética. O prazer do texto de que nos fala Roland Barthes (1996 Original francês de 1973), por exemplo, tanto pode ocorrer por meio de sentimentos positivos, alegres, leves como também daqueles negativos, tristes, pesados. Trata-se da chamada catarse, já tratada por Aristóteles, na sua Arte Poética, 384-322 a. C., e retomada por Jauss (1979).

Já na primeira página da obra $(2018$, p. 3), visualizamos o contraste entre o "você pergunta", apontando para o leitor, coautor da obra, e respondido com outras perguntas, que aparecem nas páginas seguintes (2018, p. 4 e 5), e que também dão título ao livro: O que existe? O que não existe?. Ilustra a página um barco de papel, que já constitui uma representação de um objeto do mundo real - o barco "de verdade", a sua réplica em papel, tradicional brinquedo infantil, que pode ser interpretado como índice da imaginação (por meio de um barco de papel, crianças podem se transformar em piratas e singrar os sete mares em uma bacia de água). A água funciona, na ilustração e no mundo real, também como um espelho e assim vemos o barquinho refletido, invertido. De um lado e outro da imagem do barco, as duas perguntas que dão título ao livro, também refletidas, invertidas, na água. As tonalidades esmaecidas de azul mais escuro na ilustração da água e azul mais claro, na ilustração do céu, além dos vários tons de ocre, emanando um ocaso, vão compondo a atmosfera onírica emanada pelas páginas, completadas ainda por imagens que lembram os balões de pensamento das histórias em quadrinhos e manchas redondas brancas que lembram uma visão por detrás de um vidro. Nas páginas seguintes, o jogo entre o real e o imaginário continua representado pela imagem da interação de uma leitora com o "livro de imaginação". O livro, como metonímia da literatura, representa a fonte da imaginação da leitora, ilustrada por uma criança negra com cabelos vastos 
levados pelo vento, imagem que é reforçada pelas folhas de árvores caindo. Destacam-se as cores predominantes entre as páginas duplas anteriores (p. 4-5), cujas cores já foram anteriormente mencionadas, e as cores das páginas 6-7, em que sobressaem o marrom da pele e cabelo da menina (na página 7) e o amarelo-bege da página ao lado (p. 8). O texto continua com a dicotomia existe-não existe, do ponto de vista do pensamento e da imaginação, porque para "existir" não tem de estar no mundo "de verdade", mas pode estar também no "mundo da imaginação".

Nas páginas 8 e 9, o leitor depara com uma ilustração "solar": de um lado, representações de animais, dos mais prosaicos, como um gato, um cachorro, uma galinha, ao exótico ornitorrinco (vale lembrar que este animal é tão "estranho", que ao ser descrito pela primeira vez no século XVIII, foi considerado uma "armação" da natureza, uma vez que parecia um misto de ave, roedor e anfíbio - bico de pato, rabo de castor, ...), bem como de um lápis e de um caderno, também símbolos da imaginação proporcionada pela escrita. Vale lembrar também que ao apresentar um ovo e uma galinha, retoma-se à pergunta popular e ao mesmo tempo filosófica: Quem veio primeiro, o ovo ou a galinha? Na página ímpar (p. 9), temos representados elementos do imaginário europeu (Papai Noel, fadas e gnomos) ao lado de figuras do folclore brasileiro (mula-sem-cabeça e Saci Pererê) e o universal fantasminha. Compõem ainda as imagens duas crianças (note-se um menino negro e uma menina oriental, não deixando de lado a diversidade étnico-racial), envolvidos com livros e interação pessoal, com quatro semicírculos amarelos ao fundo, evocando o sol em diferentes momentos em seu poente. Podemos dizer que o passar de páginas da obra, o ato da leitura em si, vai surpreendendo o leitor o tempo todo, ao brincar com as cores, as técnicas e as imagens representadas. Nas páginas 10-11, observamos desenhos infantis que vão dos croquis de crianças, casas, árvores e corações, bem típicos de uma geração de crianças das décadas de 1970 ou 1980, ao lado de desenhos que remetem aos emoticons e emojis, tão presentes em nossa vida hoje.

As páginas 12 e 13 da obra, já descritas acima, constituem exatamente o meio do livro, onde aparecem os grampos, e da forma como foram configuradas, constituem o "respiro" a obra. Ao mesmo tempo em que nelas o leitor vai se concretizar como coautor do texto, no momento mesmo da primeira leitura, se assim o desejar, ou noutras releituras da obra, as suas páginas vazias contrastam bastante com as páginas seguintes, em que predominam cores frias, num ambiente sombrio e tranquilo que evoca o fundo do mar, representado nas partes inferiores e a paisagem noturna, com a imagem de uma sereia negra (novamente a opção por representar brasileiramente uma personagem de origem grega), um menino loiro cavalgando um dragão e um astronauta, num planeta distante, encontrando seres extraterrestres. 
O tempo todo, vamos observando, no texto escrito, a brincadeira com as palavras, o jogo do existe e não existe e nas páginas 16 e 17 vamos deparar com ambientes familiares, com crianças brincando ao lado de adultos, provavelmente seus pais. Vale aí mencionar que a ilustradora teve o cuidado de apresentar, inclusive, uma personagem ruiva, completando-se assim um ciclo de representações de diversos biotipos e tonalidades de pele e cores dos pelos do corpo. As páginas 18 e 19 apresentam, mais uma vez, um belo diálogo entre texto imagem. Enquanto o texto verbal questiona a existência de super-heróis da forma como são criados pela mente humana, a ilustração nos mostra profissões que tradicionalmente ligadas à ajuda, como os socorristas e salva-vidas, mas traz também um gari como um herói, tendo em vista seu importante papel social, dando visibilidade a um dos profissionais mais invisíveis que encontramos. Não ficam de fora nem os animais, como os importantes cães-guias de cegos. E novamente, nas imagens, várias figuras humanas estão representados e com papéis nem sempre tão estereotipados. Notem que como cuidadores dos filhos, aparece tanto uma mulher (uma mãe?) quanto um homem (um provável pai?)

O jogo vai terminando nas páginas 20-21, quando é retomada uma das perguntas iniciais, sobre os extraterrestres, e o texto escrito não fecha a questão: afinal, o universo é tão grande, tão desconhecido ainda, como afirmar se eles existem ou não, se não há evidências científicas? Ainda é importante ressaltar que o ET representado na página 20 nada tem a ver com as tradicionais representações do ET, tanto a cinematográfica, consagrada no filme de

Steven Spielberg, quanto os marcianos verdes e de antenas criados há tanto tempo e já incorporados por várias obras que até perdemos a referência imediata de seus criadores.

O desfecho da obra não poderia ser mais feliz. A autora retoma os míticos dragões e sereias e joga para o leitor/coautor a pergunta. É ele quem tem de pensar e responder, deixando aberto o final, como bem fazem muitas obras literárias. Para ajudar ou confundir o leitor, a ilustradora nos brinda com um encontro entre dragão e sereia, charmosamente tomando um chá, em meio a um jardim repleto de margaridas e um luar maravilhoso, que parece saltar a página do livro, a nos iluminar.

\section{Descrição analítica do livro $O$ que é um livro?}

A capa de $O$ que é um livro? (RIBEIRO, 2018) traz o título da obra, acompanhado do nome das autorias do texto escrito, Ana Elisa Ribeiro, e da ilustração, Anna Cunha. No canto superior esquerdo da capa, explicita-se a série - Papel - e no canto inferior direito aparece o nome do selo, Estraladabão, e da coleção, Universidade das Crianças - UC, ambas as 
informações aparecem como logomarcas que se repetem nos demais livros da coleção, como já foi mencionado.

Já na capa, sobre fundo verde musgo em tonalidade mais clara, é possível visualizar a imagem de uma criança negra segurando um livro próximo ao seu corpo. Nota-se que é um livro de proporção gigantesca que, ao ser representado rente ao corpo da criança, também se confunde com seu próprio corpo. Essa imagem pode remeter à ideia do cuidado e da importância com o objeto livro. Além disso, ao trazer a imagem de uma criança negra, percebese a preocupação com a representação da diversidade étnica brasileira.

Nota-se que o livro segurado pela criança se encontra entreaberto. Nas folhas do corte dianteiro há um desenho de uma porta aberta, feita com traços finos, e por ela saem pássaros voando, remetendo a uma gaiola com a porta aberta.

Pode-se inferir pelo título e pela capa que se trata de um livro informativo, destinado incialmente às crianças. A metáfora visual do livro com os pássaros alçando voo dá à obra um caráter estético e poético que valoriza a produção escrita de viés informativo.

Figura 3 - Capa do livro O que é um livro?

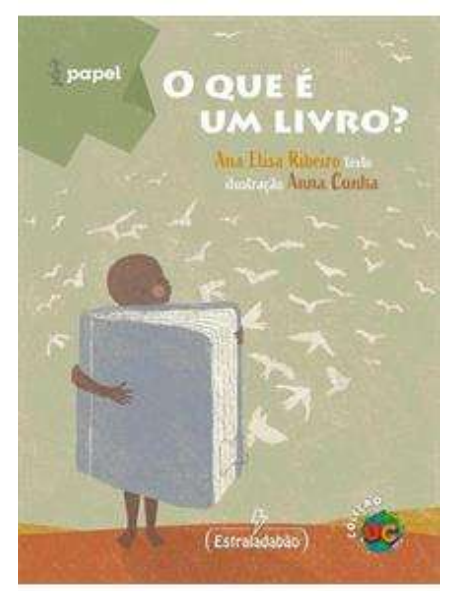

Fonte: https://www.travessa.com.br/o-que-e-um-livro/artigo/2c726ea7-b47c-46a7-8288-278160a385e2

A quarta capa, como foi dito anteriormente, segue um padrão da Coleção Universidade das Crianças. Ela traz os nomes de algumas das séries da coleção na parte superior (fantasia/corpo/arte/nomes/som/natureza/objeto), como se fossem marcadores de papel colorido. Traz ainda o restante da ilustração sangrada da capa, com um pequeno texto que situa e convida a leitura, com a repetição do título da obra. Aparecem ainda as logomarcas da coleção e do apoio do CNPq, além do registro do ISBN no canto inferior esquerdo. A segunda e terceira capa trazem imagens que se repetem na capa do livro, os pássaros alçando voo em todas as direções. Esse elemento, paratextual, contribuindo posteriormente para ampliação do pacto de leitura proposto pela obra, dando-lhe um viés mais poético também. Ressaltamos isso pelo fato 
de o elemento "pássaros voando" apresentar uma linguagem figurada, que poderá ser interpretada pelo leitor.

O verso da folha de rosto apresenta dados como: ficha catalográfica, autoridades da UFMG e editora. São apresentadas também todas as informações sobre o projeto Universidade da Criança, tais como: criação, organização e motivação, público-alvo; entre outras.

O que é um livro? foi publicado em 2018 pelo selo Estraladabão, da Editora UFMG. A ideia do livro nasceu a partir das perguntas feitas por crianças em oficinas promovidas pelo projeto Universidade das Crianças. Ana Elisa Ribeiro foi convidada para escrever um livro para a coleção por já ser uma pesquisadora do tema e Anna Cunha foi convidada para ilustrar o texto já escrito. De acordo com entrevista concedida por Ana Elisa Ribeiro, percebemos que a obra foi produzida por muitas mãos até chegar ao produto final:

No caso de $O$ que é um livro?, fiz uma pesquisa adicional (porque já estudo esse tema
há tempos) e escrevi o texto no Word. Fui mexendo, ajustando, a fim de chegar a uma
linguagem informativa e acessível, deixando a prolixidade de lado, o mais possível.
O tempo todo eu pensava na ilustração da Anna Cunha, que tem feito muitos trabalhos
na linha da história da leitura e do livro. Ela tem um traço sutil, arejado, poético ao
mesmo tempo. Era meu sonho que fosse ela. Depois que escrevi o texto, enviei para
o pessoal da editora. Houve então alguns pitacos de edição, com os quais eu concordei
quase integralmente. Umas dúvidas conceituais e tal. Enquanto isso, chamávamos a
Anna para ilustrar, mesmo sabendo que a agenda dela é difícil. Para nossa alegria, ela
topou. Em alguns meses e depois de alguns contratempos, ela entregou a ilustração já
num pdf diagramado, isto é, ela nos mostrou já quase o livro, para que víssemos como
ficaria a distribuição do texto nas páginas e cada ilustração. Para a Anna a coisa é mais
complexa. O projeto gráfico da coleção foi produzido pela Cláudia Jussan.(também
uma velha conhecida editorial). [...] Os leitores do livro são as pessoas envolvidas no
processo, incluindo revisores de texto. Houve diálogo porque tudo é sempre enviado
a todos, e todos podem dizer o que acharam. (Fragmento da entrevista cedida via e-
mail - Ana Elisa Ribeiro / 04 de agosto de 2018)

Constatamos pela entrevista que a produção do livro aconteceu de forma conjunta. Percebemos que houve interação entre escritor e ilustrador, e várias pessoas trabalharam no processamento de texto, correção, tratamento de imagens, diagramação, formatação, artefinalização de miolo e capa. Na folha de rosto, além da ficha catalográfica, constam os nomes e as funções das pessoas que participaram da produção da obra, que podemos chamar de autoria secundária ou coadjuvante.

A obra busca responder algumas perguntas de forma bem direta: "O que é um livro? Quem inventou o livro? Por que inventaram o livro?” (2018, p.3). A partir dessas perguntas surgem as respostas de forma didática e informativa, dando origem a obra. Ainda na página inicial (p.3) tem uma imagem de uma chave e de um livro com uma fechadura - metáfora da "abertura" do conhecimento. 
Na página 4, o narrador faz algumas perguntas: “Como é o livro que vem a sua cabeça? Ele é bloco de papel retangular costurado de um dos lados?" Parece que, inicialmente, tenta-se desmitificar a ideia do formato do livro, levando o leitor a pensar e até mesmo se questionar sobre o objeto livro. Será que livro sempre foi dessa forma? Como era antes? Como foi seu processo até chegar nos dias atuais? A partir dessas perguntas, o narrador vai respondendo e trazendo informações sobre os tipos de livros e escritas dos tempos das cavernas à contemporaneidade.

Nas páginas duplas, existe uma continuidade entre a parte e a ilustração, ou seja, texto verbal e texto visual se complementam. Isso ocorre o tempo todo no livro. Tomemos as páginas 4 e 5 para exemplificar. A narrativa diz que as tabuletas de argila e até as paredes das cavernas já foram recursos utilizados para registrar e escrever (p. 4). Na página 5 aparece a figura de um homem das cavernas desenhando nas paredes figuras rupestres, que são representações artísticas pré-históricas realizadas em paredes, tetos e outras superfícies de cavernas e abrigos rochosos ou mesmo sobre superfícies rochosas ao ar livre. No decorrer da leitura do livro, percebemos que o texto escrito e a ilustração continuam se completando no sentido de "casar" o texto explicativo com a ilustração.

Outro dado importante que vale ressaltar é que o livro utiliza palavras em negrito (bold) e caixa alta para destacar as palavras que foram conceituadas ou relacionadas com os tipos de livros, formatos de livros, produção dos livros e outros, como se observa na página 7 com a palavra PAPIRO escrita em negrito e em caixa alta.

Em relação às ilustrações, podemos dizer que seguem um padrão no decorrer de todas as páginas do livro. Tanto o texto escrito quanto a ilustração estão sob um fundo de tom pastel. As ilustrações seguem uma paleta de cor que não varia muito: laranja num tom terroso, cinza, preto e branco. Vale ressaltar que as ilustrações seguem um traçado simples e sofisticado ao mesmo tempo, transmitindo uma leveza nas imagens. O texto é escrito de forma gradual, informativa e acessível. Destacamos aqui, a formal gradual porque, como foi mencionado, o narrador traça uma linha histórica sobre o livro, seus processos, desde as escritas em pedras nas cavernas até os dias atuais com os livros eletrônicos (e-books). Ao final do livro, na página 23, apresenta-se novamente a imagem da capa - a criança segurando um livro.

O objeto livro representa uma tecnologia que é "capaz de armazenar as ideias, as memórias e as histórias" e o a imagem do emblemáticos "pássaros voando" remete, metaforicamente, à busca da liberdade alcançada pelo saber. 


\section{Considerações finais}

A descrição analítica das duas obras da Universidade das Crianças aqui apresentada constitui um exercício de leitura multimodal dos livros, com a intenção de fornecer a professores em formação e em serviço subsídios para o ensino e a mediação da leitura em sala de aula. Temos clareza de que nossa leitura não esgota todas as possibilidades de interpretação, uma vez que também acreditamos que cada leitor faz "uma" leitura em "um" determinado momento histórico. Portanto não há "a" leitura, "a melhor leitura" ou "a leitura correta" ou "mais correta", são sempre possibilidades ou apostas interpretativas.

Ambas as obras cumprem as funções a que se propõem. Recuperando: $O$ que existe? $O$ que não existe? trata de elementos pertencentes ao chamado mundo real e mundo imaginário, mas mostrando que o limite entre esses dois mundos, às vezes, pode ser tênue. O que é um livro?, num viés mais informativo, apresenta a história do livro em linguagem acessível ao público infantil. Entretanto, o tratamento estético proporcionado pelas ilustradoras e pelas pessoas responsáveis pelos projetos gráficos das duas obras, bem como por outros agentes do processo de produção do livro, nem sempre identificados como responsáveis por qual palpite dado, amplia as possibilidades de experiência estética com a obra.

O que existe? O que não existe? e O que é um livro? partem, ambos, de perguntas feitas por crianças, no âmbito das oficinas do Projeto Universidade das Crianças. Entretanto, os livros são construídos por meio de estratégias discursivas diferentes, que dão caráter bastante diferenciado ao produto final. Enquanto o último configura-se como um livro destinado às crianças com cunho mais informativo, ainda que com uso bastante expressivo da linguagem, o primeiro livro encaminha-se para uma proposta de cunho mais estético, com base mesmo na estratégia utilizada pela autora (o fato de ter sido publicado na série Ficção corrobora nossa análise). Vejamos que, enquanto O que é livro? busca responder de forma mais direta à pergunta feita pela criança, o primeiro livro parte de três perguntas (Existem sereias? Por que não existem dragões? Existe ET?), duas delas interrogativas afirmativas e uma delas interrogativa negativa para construir um título também com uma pergunta afirmativa e uma pergunta negativa.

Leitores perspicazes poderão observar detalhes que passarão despercebidos por leitores mais afoitos. Crianças costumam ser leitores muito perspicazes e muitas vezes nos surpreendem com seus comentários. Crianças também costumam ler livros-ilustrados com mais tempo e mais vezes, tendo assim maior condição de perceber detalhes que até mesmo especialistas não veem numa primeira leitura. Quando se faz a chamada leitura compartilhada, num círculo ou numa roda de leitura, somam-se diferentes olhares sobre um mesmo objeto livro e costuma-se ter, 
então, uma leitura mais rica, marcada pela pluralidade. Está lançado o desafio. Confrontemos nossa leitura com a de crianças e outros leitores, troquemos "figurinhas", como se pretende na segunda etapa desta pesquisa.

\section{Referências}

ARISTÓTELES. Poética. 2. ed. São Paulo: ArsPoetica, 1993.

BARTHES, Roland. O prazer do texto. Tradução J. Guinsburg. São Paulo: Perspectiva, 1996 (1976).

CAMARGO, Luís. Ilustração do livro infantil. Belo Horizonte: Editora Lê, 1995.

COPE, B.; KALANTZIS, M. Changes the Role of Schools. In: COPE, B.; KALANTZIS, M. (Org.). Multiliteracies: Literacy Learning and the Design of Social Futures. New York: Routledge, 2000. p. 121-234.

COSCARELLI, Carla. O que existe? O que não existe? Belo Horizonte: Editora UFMG, Estraladabão, 2018. Série: Ficção.

GEORGE, Patrick. Formas. São Paulo: Carochinha, 2016.

HUNT, Peter. Crítica, Teoria e Literatura infantil. Tradução Cid Knipel. São Paulo: Cosac Naify, 2010.

JAUSS, Hans Robert. O Prazer estético e as experiências fundamentais da poiésis, aisthésis e kathársis. In: LIMA, Luis Costa (Org.). A literatura e o leitor. Rio de Janeiro: Paz e Terra, 1979. p. 63-132.

KRESS, G.; VAN LEEUWEN, T. Multimodal Discourse: The modes and media of contemporary communication. London: Arnold, 2001.

KRESS, Gunther. Multimodality. A social semiotic approach to contemporary communication. New York, Routledge, 2010.

LEMKE, Jay L. Letramento metamidiático: transformando significados e mídias. In:

Trabalhos em Linguística Aplicada. Campinas, 49(2): 455-479, Jul./Dez. 2010

MENDES, André. O amor e o diabo em Ângela Lago: a complexidade do objeto artístico. Belo Horizonte: UFMG, 2007.

PAIVA, Ana Paula Mathias de. Anotações de seminário promovido pelo grupo de pesquisa MULTDICS. 8 de agosto de 2018. (notas de palestra)

RIBEIRO, Ana Elisa. O que é um livro? Ana Elisa Ribeiro, texto; ilustração Ana CunhaBelo Horizonte: Editora UFMG, Estraladabão, 2018. (Série: Papel)

ROSENTHAL, Amy Krouse; LICHTENHELD, Tom. Pato! Coelho! São Paulo: Cosac Naify, 2010 . 
SANTOS, Zaira Bomfante; PIMENTA, Sônia Maria de Oliveira. Da semiótica social à multimodalidade a orquestração de significados. In: CASA: Cadernos de Semiótica Aplicada, v.12, n.2, 2014. p. 295-324

SAINT-EXUPÉRY, Antoine de. O pequeno príncipe. Rio de Janeiro, Editora Agir, 2009. Aquarelas do autor. $48^{\mathrm{a}}$ edição / $49^{\mathrm{a}}$ reimpressão. Tradução Dom Marcos Barbosa.

SMITH, B. A.; TAN, S.; PODLASOV, A.; O'HALLORAN, K. L. Orchestration of Meaning in Multimodal Semiosis and Semiotics. Social Semiotics, 2009.

VAN DER LINDEN, Sophie. Para ler o livro ilustrado. Tradução Dorothée de Bruchard. São Paulo: Cosac Naify, 2011.

YOYO BOOKS. Vrum clap-clap. São Paulo: Yoyo Books, 2016.

Recebido em: 10/02/2019 Aceito para publicação em: 20/03/2019 